\title{
Family Physicians Report Considerable Interest in, but Limited Use of, Telehealth Services
}

\author{
Miranda A. Moore, PhD, Megan Coffman, MS, Anuradha Jetty, MPH, \\ Kathleen Klink, MD, Stephen Petterson, PhD, and Andrew Bazemore, MD, MPH
}

Purpose: Little is known about the attitudes toward and adoption of telehealth services among family physicians (FPs), the largest primary care physician group. We conducted a national survey of FPs, randomly sampled from membership organization files, to investigate use of and barriers to using telehealth services.

Methods: Using bivariate analyses, we examined how telehealth usage affected FPs' identified barriers to using telehealth services. Logistic regressions show the factors associated both with using telehealth services and with barriers to using telehealth services.

Results: Surveys reached 4980 FPs; 1557 surveys were eligible for analysis (31\% response rate). Among FPs, 15\% reported using telehealth services during 2014. After controlling for the characteristics of the physicians and their practice, FPs who were based in a rural setting, worked in a practice owned by an integrated health system or other ownership structure, and provided hospital/urgent/emergency care were more likely to use telehealth. Physician and practice characteristics by telehealth use status, sex of the physician, practice location, years in practice, care provided, and practice ownership were associated with the barriers identified.

Conclusions: Telehealth use was limited among FPs. Many of the barriers to using telehealth services cited by FPs are amenable to policy modification. (J Am Board Fam Med 2017;30:320-330.)

Keywords: Attitudes, Logistic Regression, Family Physicians, Primary Care Physicians, Surveys and Questionnaires, Telemedicine.

As health care delivery in the United States transitions to a patient-centered, value-based system with

This article was externally peer reviewed.

Submitted 22 June 2016; revised 12 December 2016; accepted 6 January 2017.

From the Department of Family and Preventive Medicine, Emory University, Atlanta, GA (MAM); the Robert Graham Center, Washington, DC (MC, AJ, SP, AB); and the Office of Academic Affiliations, Department of Veterans Affairs (KK).

Funding: This study was funded by WellPoint, Inc., under the AAFP/Graham Center Telehealth Survey contract. The funder had no control over the survey questions, sample selection, or analysis.

Prior presentation: This study was presented in part at the 43rd North American Primary Care Research Group Annual Meeting, Cancun, Mexico (October 2015); at the American Academy of Family Physicians State Legislative Conference, Minneapolis, MN (November 2015); and the Eastern Economic Association Conference, Washington, DC (February 2016).

Conflict of interest: none declared.

Corresponding author: Miranda A. Moore, PhD, Department of Family and Preventive Medicine, Emory University School of Medicine, Emory Family Medicine, $4500 \mathrm{~N}$ Shallowford Rd, Suite B, Atlanta, GA 30338 (E-mail: Miranda.Moore@Emory.edu). improved access to services, physician availability is a challenge. Telehealth could help address this problem. Although the term telebealth has been widely applied and well recognized for more than 4 decades, it lacks a singular definition. Broadly, telehealth is the use of technology to deliver health care services and information from a distance. Telehealth usage has evolved from static "store-and-forward" applications in which information, such as radiologic images, is stored and then forwarded for diagnostic review or a second opinion. Today's clinicians are providing virtual visits in real time through secure, interactive video exchange. These telehealth visits address a wide range of issues, from urgent to chronic, from primary care to subspecialty consultation, and from initial diagnosis to follow-up and management.

As the largest health care delivery platform in the United States, the primary care setting ${ }^{1}$ offers great potential for expanding telehealth use. Tele- 
health is increasingly being demonstrated as a means of expanding access to primary care ${ }^{2,3}$; enhancing core primary care features, including continuity of care $\mathrm{c}^{3,4}$ and coordination across different care settings ${ }^{4-6}$; and reducing health care costs $^{7}$ and improving health outcomes. ${ }^{8,9}$ A systematic review investigating the merits of telehealth interventions in primary care found that telehealth was generally more acceptable to patients than providers, outcomes were at least as effective as in-office care, and costs were no higher than for in-office care. $^{10}$

Improvements, however, are still needed. A recent study by Teladoc, Inc., an independent company offering mobile device-based and Internetbased medical care delivered by a physician who does not have an established relationship with the patient, found that users were not preferentially located in underserved communities, and providers had poorer performance than physician office visits on measures such as ordering diagnostic testing and prescribing appropriate antibiotics for bronchitis. ${ }^{11}$

Many of the benefits of telehealth services are realized by patients, and patient acceptability and use are increasing. Specifically, remote blood pressure monitoring devices have been shown to be easy for patients to use. ${ }^{12}$ In addition, parents of children seen for acute pediatric telehealth services in urban neighborhoods, using the Health-e-Access model, indicated they were highly satisfied with the care their child received and noted advantages over alternatives in terms of convenience, location, and service. ${ }^{13}$ In another study, primary care patients with depression indicated that participating in telepsychotherapy was acceptable. ${ }^{14}$ However, few patients had initiated or engaged in a telepsychotherapy visit.

Although we found no studies specifically investigating the cost-effectiveness of telehealth services in primary care settings, telehealth services in other settings have shown mixed results with respect to improving health outcomes and reducing costs. Acute care telehealth under the Health-e-Access program was found to be safe and effective. ${ }^{15}$ Residents of senior-living communities with access to acute care telehealth services reduced their emergency department visits without increasing other health care service utilization or mortality ${ }^{16}$; frail older adults who received telemonitoring (monitoring of a pa- tient's vital signs in a remote setting such as their home) services were found to have the same rates of hospitalizations and ED visits, and the same total days spent in a hospital, as hospital receiving usual care. ${ }^{17}$

In addition, Medicare Advantage members with heart failure and a recent hospitalization randomized to telemonitoring services provided by case managers experienced fewer inpatient days compared with the previous year. ${ }^{18}$ Postoperative telehealth visits for patients who had undergone parathyroidectomy were found to be cost-effective and efficient. ${ }^{19}$ In Europe, costs for implantable cardiac defibrillator remote follow-up visits were found to be essentially the same as those for in-office follow-up visits. ${ }^{20}$

A few studies provide information about the knowledge, attitudes, and adoption of telehealth services among health care providers. A systematic review of articles published through February 2013 investigating the perceptions of primary care clinicians, administrators, and clinical staff regarding the acceptability and feasibility of remote monitoring technology in routine adult primary care found only 15 studies meeting inclusion criteria. $^{21}$ These studies revealed many negatives: barriers to implementation; the clinical relevance of the data collected; fewer patient visits and the potential for overtreatment; insufficient time to monitor and discuss the data collected with the patient; electronic health record incompatibilities; and uncertain legal liability regarding response protocols.

In a separate study, primary care physicians agreed that teledermatology increases access to dermatologic care, improves patient care, and is acceptable to patients. ${ }^{22}$ Teledermatologists, however, indicated barriers to providing services that included delays in reimbursement, no reimbursement for services, lack of communication with referring providers, and costly and inefficient software platforms. ${ }^{23,24}$

In the primary care setting, 1 study found that clinicians were satisfied with making clinical decisions regarding follow-up care for 10 common chronic conditions when using information gathered from an online patient questionnaire instead of during an in-office visit. ${ }^{4}$ Another study of physicians and allied health professionals, which used focus group interviews to investigate the use of patient E-mails in the clinical care of patients 
with diabetes, found that most physicians did not E-mail patients directly and were uncertain about its potential to improve care. ${ }^{25}$ By contrast, the allied health professionals used E-mail frequently and perceived value in the service.

When focusing more narrowly on live interactive video visits, few studies have investigated use and provider perceptions in primary care settings. The Health-e-Access providers indicated they were comfortable collaborating with the telehealth assistants and confident that their telehealth communications met parents' needs; however, they felt slightly less confident in their remote diagnosis compared with in-person visits. ${ }^{26}$ In Spain, a binary logistic regression analysis of survey data investigating the determinants of telemedicine use in clinical practice revealed that primary care physicians placed the greatest importance on telemedicine's potential to reduce costs and on its usefulness to the medical profession. Secondary explanatory factors were the perception of the security of medical information and confidentiality, and the patients' predisposition toward telemedicine. The physician's own opinion formed a third set of factors influencing the use of telemedicine. $^{27}$

In summary, while evidence does show that advances have been made in the use of telehealth in primary care settings, little is known about the penetration of the use of various telehealth methods, that is, store and forward versus live interactive video; the characteristics of the users versus the nonusers; or the factors associated with identified barriers to use.

\section{Methods}

To address this overall lack of information about telehealth, we designed a survey to investigate whether and how family physicians (FPs) used telehealth services. The survey was fielded to a randomly selected, representative sample of FPs and collected information on the individual and practice characteristics of FPs, their use of telehealth services, and the barriers to using telehealth services.

\section{Survey Development}

The survey instrument was developed with guidance from (1) a review of the literature on telehealth and primary care conducted in $2013,{ }^{28}$ (2) an expert panel discussion convened at the Robert Graham Center on January 23, 2014, and (3) an expert survey methodologist from RTI International. The instrument and study protocol were approved by the institutional review board of the American Academy of Family Physicians (AAFP), and all human participants consented when they returned the survey. After field testing the instrument using a small group of FPs, the final survey instrument was reduced to 30 questions separated into 5 sections (See Online Appendix). These sections focused on (1) physician characteristics, (2) practice characteristics, (3) attitudes toward and barriers to using telehealth, (4) use of telehealth among telehealth users, and (5) beliefs about telehealth, with separate sections for users and nonusers. The survey provided a specific definition of telebealth that focused on primary care services, primary care and

\title{
Figure 1. Definition of telehealth.
}

\author{
Telehealth is the use of medical information exchanged from one location to another \\ via electronic communications to improve a patient's health. We are using \\ telemedicine and telehealth interchangeably. For the purpose of this project, we are \\ defining telehealth services as: \\ 1. Primary care services: this service involves a physician providing care for a patient \\ (not necessarily a patient in their practice) through the use of live interactive video; \\ and/or \\ 2. Primary care and specialist referral services: this service usually begins with a \\ primary care provider who consults with a specialist through the use of live \\ interactive video; \\ and/or \\ 3. Sharing of diagnostic images, vital signs, video clips, or patient data between a \\ primary care provider and specialist when the specialist and patient are not in the \\ same location (sometimes referred to as store and forward).
}


specialist referral services, and the sharing of electronic health data between a primary care provider and specialist (Figure 1).

\section{Survey Sample}

We drew a random sample of 9000 FPs in direct patient care from the 2014 American Medical Association (AMA) Physician Masterfile. To ensure sufficient responses from rural FPs, we oversampled rural FPs at a rate of 2 to 1 . Because the AMA Physician Masterfile has been known to have outdated addresses, this sample was then linked with AAFP membership data in an effort to obtain current mailing addresses. The linkage produced a list of 5119 FPs who are members of the AAFP.

\section{Survey Administration}

From this sample, 5000 FPs were mailed in January 2015 an introductory letter along with the survey questionnaire and a $\$ 2$ bill as an incentive to complete the survey. Approximately 10 business days later, an E-mail reminder was sent to the nonrespondents containing a link to an online version of the questionnaire. Two additional follow-up communications were sent to nonrespondents over the next 6 weeks. Data collection closed after 8 weeks.

\section{Measures}

To determine whether an FP provided telehealth services, the survey asked whether they had used telehealth services in the past 12 months (ie, calendar year 2014) and if so, "Approximately how many times in the past 12 months did you engage or refer your patients for a telehealth consultation?" Users were also asked to indicate their (1) method of use (non-mutually exclusive categories of real-time interactive video, shared computer screen images with audio, and stored or forwarded image or text transmission), (2) clinical purpose of use (non-mutually exclusive categories of diagnosis or treatment, second opinion, follow-up, chronic disease management, emergency care, and administrative purposes), and (3) the type of clinicians referred via telehealth (non-mutually exclusive categories of specialists, other FPs, general internal medicine physicians, mental health treatment providers, physical therapists, and dieticians). In addition, both users and nonusers were asked to identify barriers to telehealth use from a nonmutually exclusive list including cost of equip- ment, lack of training on how to use telehealth, reimbursement by insurers, and liability issues with telehealth.

\section{Statistical Analyses}

Sampling weights were used in all analyses so the estimates were representative of FPs in direct patient care across the United States, not just AAFP members. Specifically, the sample was weighted to account for the oversampling of rural physicians. We also adjusted the weights for the underrepresentation of international medical school graduates, younger physicians, and osteopathic physicians among respondents compared with all FPs in the AMA Physician Masterfile. Descriptive statistics were computed for select items on the survey instrument. The total number of responses and percentages are reported for categorical variables, with means and standard deviations reported for continuous variables ( $\mathrm{Ta}$ ble 1). The results are presented separately for the nonrespondents, the total sample, telehealth users, and nonusers. The nonrespondent sample is distributed similar to the respondent sample; thus, the respondents should be a good representation of the population of US family physicians. Bivariate analysis was performed to examine statistically significant differences between the users and nonusers of telehealth, using $\chi^{2}$ tests for categorical variables and analysis of variance for continuous variables. Logistic regression was used to investigate the factors associated with using telehealth services (Table 2) and with identifying each barrier to using telehealth (Table 3). The data analysis was conducted using Stata 14.0 (StataCorp, College Station, TX).

The survey obtained basic demographic and practice characteristics from respondents: years in practice, practice location, use of electronic health record, and practice size. Based on the number of years in practice, respondents were categorized into 4 groups: (1) 0 to 10 years, (2) 11 to 20 years, (3) 21 to 30 years, and (4) $>31$ years. Most respondents indicated they provided general primary care. Respondents who provided hospital, urgent, or emergency care and "other" care were combined into a single "other" category. Ownership of the primary practice location was categorized as "privately owned practice," a "hospital- or health system-owned practice," and "integrated health system” (eg, Kaiser Permanente), 
Table 1. Comparison of Demographic Characteristics and Barriers to Telehealth Use in 2014 for Family Physicians Responding to the January 2015 Robert Graham Center Survey, ${ }^{*}$ by Telehealth Use

\begin{tabular}{|c|c|c|c|c|c|}
\hline Characteristic & $\begin{array}{l}\text { Nonrespondents } \\
\quad(\mathrm{n}=3443)\end{array}$ & $\begin{array}{l}\text { All Respondents } \\
\quad(\mathrm{n}=1557)\end{array}$ & $\begin{array}{l}\text { Telehealth Users } \\
\qquad(\mathrm{n}=225)\end{array}$ & $\begin{array}{l}\text { Nonusers } \\
(\mathrm{n}=1332)\end{array}$ & $P$ Value $^{\dagger}$ \\
\hline Sex & & & & & .720 \\
\hline Female & $1477(42.9)$ & $588(41.0)$ & $90(42.3)$ & $498(40.8)$ & \\
\hline Male & $1966(57.1)$ & $969(59.0)$ & $135(57.7)$ & $834(59.2)$ & \\
\hline Type of medical degree & & & & & .120 \\
\hline Allopathic & $3109(90.3)$ & $1410(83.9)$ & $210(88.7)$ & $1200(83.3)$ & \\
\hline Osteopathic & $334(9.7)$ & $147(16.1)$ & $15(11.3)$ & $132(16.7)$ & \\
\hline \multicolumn{6}{|l|}{ Location of medical school } \\
\hline United States & $2748(79.8)$ & $1371(79.7)$ & $202(81.7)$ & $1169(79.4)$ & .556 \\
\hline International & $695(20.2)$ & $186(20.3)$ & $23(18.3)$ & $163(20.6)$ & \\
\hline \multicolumn{6}{|l|}{ Practice location } \\
\hline Urban & $2834(82.3)$ & $1047(83)$ & $112(73.9)$ & $935(87.8)$ & $<.001$ \\
\hline Rural & $609(17.7)$ & $510(17)$ & $113(26.1)$ & $397(15.1)$ & \\
\hline \multicolumn{6}{|l|}{ Years in practice } \\
\hline $0-10$ & & $361(28.1)$ & $62(34.6)$ & $299(27.2)$ & .060 \\
\hline $11-20$ & & $513(33.9)$ & $64(27.9)$ & $449(34.7)$ & .070 \\
\hline $21-30$ & & $411(23.7)$ & $64(25.9)$ & $347(23.4)$ & .450 \\
\hline$\geq 31$ & & $256(14.3)$ & $33(11.7)$ & $223(14.7)$ & .230 \\
\hline Missing data & & $16(1.0)$ & $2(0.5)$ & $14(1.1)$ & \\
\hline Electronic health record use & & & & & .006 \\
\hline Currently a user & & $1440(93.0)$ & $218(97.3)$ & $1222(91.9)$ & \\
\hline Not current a user & & $107(6.5)$ & $5(2.2)$ & $102(7.6)$ & \\
\hline Missing data & & $10(0.5)$ & $2(0.5)$ & $8(0.5)$ & \\
\hline \multicolumn{6}{|l|}{ Type of care provided } \\
\hline General primary care & & $1330(84.4)$ & $175(76.4)$ & $1155(85.5)$ & .004 \\
\hline $\begin{array}{l}\text { Hospital/urgent/emergency care } \\
\text { or other }\end{array}$ & & $227(14.3)$ & $46(21.7)$ & $161(13.3)$ & \\
\hline Missing data & & $20(1.3)$ & $4(1.9)$ & $16(1.2)$ & \\
\hline \multicolumn{6}{|l|}{ Family physicians at the practice site } \\
\hline $1-5$ & & 1067 (68.6) & $138(59.1)$ & $929(70.0)$ & .005 \\
\hline$\geq 6$ & & $471(30.2)$ & $85(39.5)$ & $386(28.8)$ & \\
\hline Missing data & & $19(1.2)$ & $2(0.9)$ & $17(1.2)$ & \\
\hline Practice ownership & & & & & $<.001$ \\
\hline Private & & $572(36.6)$ & $52(21.9)$ & $520(38.6)$ & \\
\hline $\begin{array}{l}\text { Owned by a hospital or health } \\
\text { system }\end{array}$ & & $662(41.1)$ & $95(37.6)$ & $567(41.6)$ & \\
\hline Integrated health system & & $75(5.6)$ & $19(11.3)$ & $56(4.8)$ & \\
\hline Other & & $227(15.4)$ & $58(29.0)$ & $169(13.5)$ & \\
\hline Missing data & & $21(1.3)$ & $1(0.2)$ & $20(1.5)$ & \\
\hline \multicolumn{6}{|l|}{ Barriers to using telehealth } \\
\hline Any barrier from the list & & $1382(88.8)$ & $118(83.6)$ & $1194(89.6)$ & .008 \\
\hline Cost of equipment & & $704(45.4)$ & $78(33.6)$ & $626(47.0)$ & .001 \\
\hline $\begin{array}{l}\text { Lack of training on how to use } \\
\text { telehealth }\end{array}$ & & $828(53.7)$ & $91(40.7)$ & $737(55.5)$ & $<.001$ \\
\hline Reimbursement by insurers & & $829(53.3)$ & $102(43.2)$ & $727(54.7)$ & .004 \\
\hline $\begin{array}{l}\text { Liability issues associated with } \\
\text { telehealth }\end{array}$ & & $595(41.1)$ & $56(26.6)$ & $539(43.2)$ & $<.001$ \\
\hline Other & & $325(19.9)$ & $56(22.2)$ & $269(19.6)$ & .400 \\
\hline
\end{tabular}

Data are n (\%). Weighted percentages may not add up to 100 because of rounding and non-mutually exclusive categories.

* Respondents were from among a random sample of 5000 family physicians in direct patient care from the 2014 American Medical Association Physician Masterfile, with oversampling of rural family physicians at a rate of 2 to 1 .

${ }^{\dagger} P$ values were calculated using the $\chi^{2}$ test of significance between telehealth users and nonusers. 
Table 2. Factors Associated With Telehealth Use in 2014 for Family Physicians Responding to the January 2015 Robert Graham Center Survey*

\begin{tabular}{|c|c|c|}
\hline Variable & Odds Ratio & Confidence Interval \\
\hline \multicolumn{3}{|l|}{ Sex } \\
\hline Female & 1.07 & $0.75-1.54$ \\
\hline Male & Reference & \\
\hline \multicolumn{3}{|l|}{ Type of medical degree } \\
\hline Allopathic & Reference & \\
\hline Osteopathic & 0.57 & $0.31-1.02$ \\
\hline \multicolumn{3}{|l|}{ Location of medical school } \\
\hline United States & Reference & \\
\hline International & 0.8 & $0.48-1.32$ \\
\hline \multicolumn{3}{|l|}{ Practice location } \\
\hline Urban & Reference & \\
\hline Rural & 3.05 & $2.19-4.25$ \\
\hline \multicolumn{3}{|l|}{ Years in practice } \\
\hline $1-10$ & Reference & \\
\hline $11-20$ & 0.66 & $0.43-1.01$ \\
\hline $21-30$ & 0.87 & $0.55-1.37$ \\
\hline$>31$ & 0.62 & $0.36-1.08$ \\
\hline \multicolumn{3}{|l|}{ Electronic health record use } \\
\hline Currently a user & 3.42 & $1.22-9.65$ \\
\hline Not currently a user & Reference & \\
\hline \multicolumn{3}{|l|}{ Type of care provided } \\
\hline Hospital/urgent/emergency care or other care & Reference & \\
\hline General primary care & 0.51 & $0.33-0.80$ \\
\hline \multicolumn{3}{|l|}{ Family physicians at the practice site } \\
\hline $1-5$ & Reference & \\
\hline$\geq 6$ & 1.32 & $0.93-1.89$ \\
\hline \multicolumn{3}{|l|}{ Practice ownership } \\
\hline Private & Reference & \\
\hline Hospital health system & 1.26 & $0.81-1.95$ \\
\hline Integrated health system & 3.53 & $1.79-6.98$ \\
\hline Other & 3.56 & $2.17-5.85$ \\
\hline Constant & 0.047 & $0.02-0.15$ \\
\hline
\end{tabular}

*Respondents were from among a random sample of 5000 family physicians in direct patient care from the 2014 American Medical Association Physician Masterfile, with oversampling of rural family physicians at a rate of 2 to 1 . There are 1508 observations.

or "other." From the AMA Masterfile, we identified the FPs' medical school location (international or in the United States) and their type of medical degree: osteopathic (DO) or allopathic (MD). Addresses were geocoded, and census tract information was used to determine the urban or rural location of each practice setting.

\section{Results}

Characteristics of Telehealth Users and Nonusers

From the 5000 FPs targeted, 1630 responded. The final analysis sample consists of 1557 respondents (response rate, $31.1 \%$ ) who had a valid survey identifier (38 did not) and reported engaging in direct primary care $(35$ were either not in direct patient care or chose not to answer this question and were excluded).

Approximately $15 \%$ of the sample $(\mathrm{n}=225)$ indicated they had used telehealth services in calendar year 2014. Telehealth users differed from nonusers in many ways. They were more likely to be located in a rural setting ( $26 \%$ vs $15 \% ; P<.001)$, to use an electronic health record $(97 \%$ vs $92 \% ; P=$ .006), and to work in a practice with $\geq 6 \mathrm{FPs}$ ( $40 \%$ vs $29 \% ; P=.0047)$. In addition, telehealth users 
Table 3. Factors Associated With Indicating That the Item Is a Barrier to Using Telehealth in 2014 for Family Physicians Responding to the January 2015 Robert Graham Center Survey*

\begin{tabular}{|c|c|c|c|c|c|c|c|c|c|c|}
\hline \multirow[b]{2}{*}{ Variable } & \multicolumn{2}{|r|}{ Any } & \multicolumn{2}{|r|}{ Cost } & \multicolumn{2}{|c|}{ Training } & \multicolumn{2}{|c|}{ Reimbursement } & \multicolumn{2}{|c|}{ Liability Issues } \\
\hline & $\begin{array}{l}\text { Odds } \\
\text { Ratio }\end{array}$ & $\begin{array}{l}\text { Confidence } \\
\text { Interval }\end{array}$ & $\begin{array}{l}\text { Odds } \\
\text { Ratio }\end{array}$ & $\begin{array}{l}\text { Confidence } \\
\text { Interval }\end{array}$ & $\begin{array}{l}\text { Odds } \\
\text { Ratio }\end{array}$ & $\begin{array}{l}\text { Confidence } \\
\text { Interval }\end{array}$ & $\begin{array}{l}\text { Odds } \\
\text { Ratio }\end{array}$ & $\begin{array}{l}\text { Confidence } \\
\text { Interval }\end{array}$ & $\begin{array}{l}\text { Odds } \\
\text { Ratio }\end{array}$ & $\begin{array}{l}\text { Confidence } \\
\text { Interval }\end{array}$ \\
\hline Telehealth user & 0.51 & $0.33-0.77$ & 0.63 & $0.46-0.86$ & 0.54 & $0.40-0.73$ & 0.82 & $0.61-1.11$ & 0.56 & $0.40-0.78$ \\
\hline \multicolumn{11}{|l|}{ Sex } \\
\hline Female & 1.10 & $0.76-1.58$ & 0.99 & $0.79-1.24$ & 1.52 & $1.21-1.91$ & 0.97 & $0.78-1.22$ & 1.11 & $0.88-1.40$ \\
\hline Male & \multicolumn{2}{|c|}{ Reference } & \multicolumn{2}{|c|}{ Reference } & \multicolumn{2}{|c|}{ Reference } & \multicolumn{2}{|c|}{ Reference } & \multicolumn{2}{|c|}{ Reference } \\
\hline \multicolumn{11}{|l|}{ Type of medical degree } \\
\hline Allopathic & \multicolumn{2}{|c|}{ Reference } & \multicolumn{2}{|c|}{ Reference } & \multicolumn{2}{|c|}{ Reference } & \multicolumn{2}{|c|}{ Reference } & \multicolumn{2}{|c|}{ Reference } \\
\hline Osteopathic & 0.93 & $0.51-1.69$ & 1.18 & $0.82-1.68$ & 1.02 & $0.71-1.47$ & 0.79 & $0.55-1.13$ & 1.04 & $0.72-1.50$ \\
\hline \multicolumn{11}{|l|}{ Location of medical school } \\
\hline United States & \multicolumn{2}{|c|}{ Reference } & \multicolumn{2}{|c|}{ Reference } & \multicolumn{2}{|c|}{ Reference } & \multicolumn{2}{|c|}{ Reference } & \multicolumn{2}{|c|}{ Reference } \\
\hline International & 0.68 & $0.41-1.13$ & 0.82 & $0.58-1.15$ & 0.75 & $0.54-1.06$ & 0.93 & $0.66-1.30$ & 1.57 & $1.12-2.19$ \\
\hline \multicolumn{11}{|l|}{ Practice location } \\
\hline Urban & \multicolumn{2}{|c|}{ Reference } & & eference & & eference & & eference & & eference \\
\hline Rural & 1.14 & $0.78-1.65$ & 1.11 & $0.88-1.39$ & 0.95 & $0.76-1.20$ & 0.84 & $0.67-1.06$ & 0.67 & $0.53-0.85$ \\
\hline Years in practice & & & & & & & & & & \\
\hline $1-10$ & & eference & & eference & & eference & & eference & & eference \\
\hline $11-20$ & 0.86 & $0.53-1.38$ & 0.86 & $0.65-1.14$ & 0.69 & $0.51-0.92$ & 1.02 & $0.77-1.36$ & 0.77 & $0.57-1.02$ \\
\hline $21-30$ & 0.78 & $0.47-1.28$ & 0.71 & $0.52-0.97$ & 0.66 & $0.48-0.90$ & 0.96 & $0.71-1.31$ & 0.76 & $0.56-1.04$ \\
\hline$>31$ & 0.68 & $0.38-1.22$ & 0.71 & $0.49-1.01$ & 0.62 & $0.43-0.89$ & 0.81 & $0.56-1.16$ & 0.74 & $0.52-1.08$ \\
\hline Electronic health record use & & & & & & & & & & \\
\hline Currently a user & 1.27 & $0.67-2.40$ & 0.82 & $0.54-1.25$ & 1.14 & $0.75-1.73$ & 1.17 & $0.77-1.78$ & 0.86 & $0.56-1.31$ \\
\hline Not currently a user & & eference & & eference & & eference & & eference & & eference \\
\hline Type of care provided & & & & & & & & & & \\
\hline $\begin{array}{l}\text { Hospital/urgent/ } \\
\text { emergency care or } \\
\text { other care }\end{array}$ & & eference & & eference & & eference & & eference & & eference \\
\hline General primary care & 1.41 & $0.91-2.19$ & 1.53 & $1.12-2.09$ & 1.61 & $1.18-2.18$ & 1.68 & $1.24-2.27$ & 0.96 & $0.70-1.32$ \\
\hline $\begin{array}{l}\text { Family physicians at the } \\
\text { practice site }\end{array}$ & & & & & & & & & & \\
\hline $1-5$ & & eference & & eference & & eference & & eference & & eference \\
\hline$\geq 6$ & 0.96 & $0.66-1.39$ & 0.83 & $0.66-1.05$ & 1.05 & $0.83-1.32$ & 0.96 & $0.77-1.21$ & 0.8 & $0.63-1.02$ \\
\hline Practice ownership & & & & & & & & & & \\
\hline Private & & eference & & eference & & eference & & eference & & eference \\
\hline Hospital health system & 0.91 & $0.61-1.35$ & 0.78 & $0.62-1.00$ & 0.89 & $0.70-1.14$ & 0.84 & $0.66-1.07$ & 0.90 & $0.70-1.14$ \\
\hline Integrated health system & 0.7 & $0.33-1.45$ & 0.49 & $0.29-0.84$ & 1.08 & $0.65-1.81$ & 0.55 & $0.33-0.92$ & 0.74 & $0.43-1.25$ \\
\hline Other & 0.91 & $0.55-1.53$ & 0.91 & $0.66-1.25$ & 0.84 & $0.60-1.16$ & 0.51 & $0.37-0.71$ & 0.67 & $0.48-0.95$ \\
\hline Constant & 7.54 & $3.18-17.88$ & 1.11 & $0.63-1.94$ & 0.99 & $0.56-1.74$ & 0.96 & $0.55-1.68$ & 1.24 & $0.70-2.18$ \\
\hline
\end{tabular}

*Respondents were from among a random sample of 5000 family physicians in direct patient care from the 2014 American Medical Association Physician Masterfile, with oversampling of rural family physicians at a rate of 2 to 1 . There are 1508 observations.

were less likely to work in a privately owned practice $(22 \%$ vs $39 \% ; P<.001)$ and to provide general primary care to their patients $(76 \%$ vs $86 \% ; P=$ .004).

Telehealth users were less likely to report at least 1 barrier to providing telehealth services in their office than nonusers ( $84 \%$ of users vs $90 \%$ of nonusers; $P=.008$ ). Lack of training and reim- bursement were the most common barriers identified by both users and nonusers.

\section{Methods and Clinical Purpose of Telehealth Use}

FPs who used telehealth did so infrequently; with $22 \%$ using it 1 to 2 times in calendar year 2014, and another $26 \%$ using it 3 to 5 times (Table 4). Almost half of telehealth users indicated their telehealth 
Table 4. Characteristics of Telehealth Users in $2014(\mathrm{n}=225)$ among Family Physicians Responding to the January 2015 Robert Graham Center Survey*

\begin{tabular}{|c|c|c|}
\hline Characteristics of Telehealth Use & & \\
\hline \multicolumn{3}{|l|}{ Frequency (times per year) } \\
\hline $1-2$ & 49 & $(22.5)$ \\
\hline $3-5$ & 59 & $(25.7)$ \\
\hline $6-10$ & 27 & $(9.3)$ \\
\hline $11-15$ & 14 & $(6.0)$ \\
\hline $16-20$ & 6 & $(2.2)$ \\
\hline$>20$ & 36 & $(20.0)$ \\
\hline Missing data & 34 & $(14.2)$ \\
\hline \multicolumn{3}{|l|}{ Method } \\
\hline Real-time video & 112 & $(48.7)$ \\
\hline Shared computer screen images with audio & 20 & $(10.8)$ \\
\hline Stored or forwarded image or text transmission & 60 & $(30.7)$ \\
\hline Other & 26 & $(9.6)$ \\
\hline Missing data & 39 & $(16.7)$ \\
\hline \multicolumn{3}{|l|}{ Clinical purpose } \\
\hline Diagnosis or treatment & 122 & $(55.2)$ \\
\hline Second opinion & 45 & $(19.9)$ \\
\hline Follow-up & 49 & $(20.9)$ \\
\hline Chronic disease management & 54 & $(25.7)$ \\
\hline Emergency care & 42 & $(16.1)$ \\
\hline Administrative purpose & 11 & $(5.7)$ \\
\hline Other & 30 & $(13.0)$ \\
\hline Missing data & 28 & $(12.3)$ \\
\hline \multicolumn{3}{|l|}{ Types of physicians or clinicians referred } \\
\hline Specialists & 149 & $(68.1)$ \\
\hline Other family physicians & 12 & $(6.0)$ \\
\hline General internal medicine physicians & 10 & $(5.7)$ \\
\hline Pediatricians & 7 & $(3.3)$ \\
\hline Mental health treatment providers & 70 & $(28.0)$ \\
\hline Physical therapists & 12 & $(6.4)$ \\
\hline Dieticians & 16 & $(8.9)$ \\
\hline Other & 24 & $(9.3)$ \\
\hline Missing data & 39 & $(17.3)$ \\
\hline
\end{tabular}

Data are $\mathrm{n}(\%)$. Weighted percentages may not add up to 100 because of rounding and non-mutually exclusive categories.

*Respondents were from among a random sample of 5000 family physicians in direct patient care from the 2014 American Medical Association Physician Masterfile, with oversampling of rural family physicians at a rate of 2 to 1 .

usage involved real-time interactive video, $31 \%$ used store-and-forward image or text transmission, and $11 \%$ used shared computer screen images with audio. Over half $(55 \%)$ of the FPs who used telehealth services in calendar year 2014 indicated they used it for diagnosis and/or treatment purposes. Other common purposes included chronic disease management, follow-up, second opinions, and emergency care.

The majority of the FPs who reported using telehealth services used them to refer their patients to specialists (68\%). Approximately $28 \%$ of tele- health users referred their patients to mental health treatment providers.

\section{Factors Associated with Telehealth Use}

Logistic regression results showed that the use of telehealth was significantly associated with practice location, practice size, the type of care provided, and the ownership of the physician's practice (Table 2). FPs practicing in a rural setting had 3 times higher odds of using telehealth in the past year than FPs in urban settings (odds ratio [OR], 3.05; 95\% confidence interval [CI], 2.19-4.25). FPs who pro- 
vide general primary care were less likely to use telehealth (OR, 0.51; 95\% CI, 0.33-0.80). FPs working in practices owned by an integrated health system were more likely to use telehealth than those in privately owned practices (OR, 3.53; 95\% CI, 1.79-6.98).

\section{Factors Associated with Identifying Barriers to Telebealth Use}

As expected, being a telehealth user was associated with lower odds of identifying any barrier to providing telehealth (OR, 0.51; 95\% CI, 0.33-0.77) (Table 3). FPs providing general primary care were significantly more likely to identify cost (OR, 1.53; 95\% CI, 1.12-2.09), training (OR, 1.61; 95\% CI, $1.18-2.18$ ), and reimbursement (OR, 1.68; 95\% CI, 1.24-2.27) as barriers to using telehealth. Compared with FPs practicing in a private practice, FPs practicing in an integrated health systems (OR, 0.55; 95\% CI, 0.33-0.92) and FPs in practices with some other type of practice ownership (OR, 0.51; 95\% CI, 0.37-0.71) were less likely to identify reimbursement as a barrier to use. Female FPs were more likely to identify training as a barrier (OR, 1.52; 95\% CI, 1.21-1.91).

Compared with FPs who had practiced for $\leq 10$ years, FPs who had practiced longer had lower odds of identifying training as a barrier to providing telehealth services. Rural FPs had 33\% lower odds than their urban counterparts of identifying liability issues as a barrier (OR, 0.67; 95\% CI, 0.56-1.06). By contrast, international medical graduates, compared with US medical graduates, had $57 \%$ higher odds of identifying liability issues as a barrier to providing telehealth services (OR, 1.57 ; $95 \%$ CI, 1.12-2.19).

\section{Discussion}

As telehealth technological capabilities improve and the demand for accessible health care services increases, telehealth represents an important venue to meet the needs of patients. Few previous studies have examined the use of telehealth in primary care settings. To our knowledge, our study represents the first in-depth assessment of these issues using a nationally representative sample.

The findings highlight the low adoption rate of telehealth services in the provision of primary care. Fifteen percent of FPs used telehealth services in the preceding 12 months (calendar year 2014), and many of the users did so infrequently. The greater use of telehealth services by rural FPs may reflect the greater demand among rural patients as a result of travel impediments and provider shortages. ${ }^{29}$

Although AMD Global Telemedicine, a provider of telemedicine equipment and technology, believes providing telehealth services does not require a physician to be "tech-savvy," 30 FPs who currently use an electronic health record are more likely to use telehealth services. Economies of scale, which reduce barriers associated with cost, may be the reason FPs in larger practices and integrated health care systems were more likely to use telehealth. A surprisingly large $84 \%$ of telehealth users and $90 \%$ of nonusers reported at least 1 barrier to providing telehealth services in their practice.

Several limitations must be considered when interpreting these findings. With a response rate of about $31 \%$ and only $15 \%$ of the respondents indicating they had used telehealth services in the past year, our results on the use of telehealth are based on the responses of only 225 FPs. In addition, as with all surveys asking respondents to report on past activity, recall bias is a limitation. Although the survey design was based on a robust review of the literature, and a survey expert was engaged to validate the survey, survey question order and phrasing could affect the way the FPs responded to the questions.

If telehealth services are to have a major impact in the primary care setting, more physicians will need to become experienced in the use of these services. Many impediments to wider adoption exist; however, many of these barriers are amenable to policy modifications. One suggestion for overcoming the training barrier is for family medicine residency programs to ensure that graduating residents are offered opportunities to use telehealth services. To address issues of reimbursement, governmental and private payers could engage in outreach efforts to increase awareness of their current allowed payments for telehealth and either expand the types of telehealth services currently eligible for payment or develop new ways to reimburse telehealth services.

The authors thank WellPoint/Anthem, Inc., for funding of this survey and the American Academy of Family Physicians for fielding the survey. Claire Gibbons, $\mathrm{PhD}$, provided valuable work on the background for this article. Douglas Kamerow, MD, MPH, provided many edits to the text of the article. 
Murrey Olmsted, PhD, a survey methodologist at RTI International, provided valuable help with the survey design.

To see this article online, please go to: bttp://jabfm.org/content/ 30/3/320.full.

\section{References}

1. Green LA, Fryer GE, Yawn BP, Lanier D, Dovey SM. The ecology of medical care revisited. N Engl J Med 2001;344:2021-5.

2. Uscher-Pines L, Mehrotra A. Analysis of Teladoc use seems to indicate expanded access to care for patients without prior connection to a provider. Health Aff (Millwood) 2014;33:258-64.

3. Hickson R, Talbert J, Thornbury WC, Perin NR, Goodin AJ. Online medical care: the current state of "eVisits" in acute primary care delivery. Telemed J E Health 2015;21:90-6.

4. Dixon RF, Rao L. Asynchronous virtual visits for the follow-up of chronic conditions. Telemed J E Health 2014;20:669-72.

5. Biese K, Lamantia M, Shofer F, et al. A randomized trial exploring the effect of a telephone call follow-up on care plan compliance among older adults discharged home from the emergency department. Acad Emerg Med 2014;21:188-95.

6. Wakefield B, Holman J, Ray A, et al. Outcomes of a home telehealth intervention for patients with heart failure. J Telemed Telecare 2009;15:46-50.

7. Seto E. Cost comparison between telemonitoring and usual care of heart failure: a systematic review. Telmed J E Health 2008;14:679-86.

8. Nundy S, Dick J, Chou C, Nocon R, Chin M, Peek M. Mobile phone diabetes project led to improved glycemic control and net savings for Chicago plan participants. Health Aff (Millwood) 2014;33:265-72.

9. Ronis SD, McConnochie KM, Wang H, Wood NE. Urban telemedicine enables equity in access to acute illness care. Telemed J E Health 2017;23:105-12.

10. Bashshur RL, Howell JD, Krupinski EA, Harms KM, Bashshur N, Doarn CR. The empirical foundations of telemedicine interventions in primary care. Telemed J E Health 2016;22:342-75.

11. Uscher-Pines L, Mulcahy A, Cowling D, Hunter G, Burns R, Mehrotra A. Access and quality of care in direct-to-consumer telemedicine. Telemed J E Health 2016;22:282-7.

12. Abdullah A, Liew SM, Hanafi NS, et al. What influences patients' acceptance of a blood pressure telemonitoring service in primary care? A qualitative study. Patient Prefer Adherence 2016;10:99-106.

13. McIntosh S, Cirillo D, Wood N, Dozier AM, Alarie C, McConnochie KM. Patient evaluation of an acute care pediatric telemedicine service in urban neighborhoods. Telemed J E Health 2014;20:1121-6.

14. Deen TL, Fortney JC, Schroeder G. Patient acceptance of and initiation and engagement in telepsy- chotherapy in primary care. Psychiatr Serv 2013;64: 380-4.

15. McConnochie KM, Ronis SD, Wood NE, Ng PK. Effectiveness and safety of acute care telemedicine for children with regular and special healthcare needs. Telemed J E Health 2015;21:611-21.

16. Shah MN, Wasserman EB, Wang H, et al. Highintensity telemedicine decreases emergency department use by senior living community residents. Telemed J E Health 2016;22:251-8.

17. Takahashi PY, Pecina JL, Upatising B, et al. A randomized controlled trial of telemonitoring in older adults with multiple health issues to prevent hospitalizations and emergency department visits. Arch Intern Med 2012;172:773-9.

18. Wade MJ, Desai AS, Spettell CM, et al. Telemonitoring with case management for seniors with heart failure. Am J Manag Care 2011;17:e71-9.

19. Urquhart AC, Antoniotti NM, Berg RL. Telemedicine-an efficient and cost-effective approach in parathyroid surgery. Laryngoscope 2011;121:1422-5.

20. Heidbuchel H, Hindricks G, Broadhurst P, et al. EuroEco (European Health Economic Trial on Home Monitoring in ICD Patients): a provider perspective in five European countries on costs and net financial impact of follow-up with or without remote monitoring. Eur Heart J 2015;36:158-69.

21. Davis MM, Freeman M, Kaye J, Vuckovic N, Buckley DI. A systematic review of clinician and staff views on the acceptability of incorporating remote monitoring technology into primary care. Telemed J E Health 2014;20:428-38.

22. Barbieri JS, Nelson CA, Bream KD, Kovarik CL. Primary care providers' perceptions of mobile storeand-forward teledermatology. Dermatol Online J 2015;21(8). pii: 13030/qt2jt0h05w.

23. Armstrong AW, Kwong MW, Ledo L, Nesbitt TS, Shewry SL. Practice models and challenges in teledermatology: a study of collective experiences from teledermatologists. PloS One 2011;6:e28687.

24. Giambrone D, Rao BK, Esfahani A, Rao S. Obstacles hindering the mainstream practice of teledermatopathology. J Am Acad Dermatol 2014;71:772-80.

25. Popeski N, McKeen C, Khokhar B, et al. Perceived barriers to and facilitators of patient-to-provider e-mail in the management of diabetes care. Can J Diabetes 2015;39:478-83.

26. McConnochie K, Wood N, Herendeen N, ten Hoopen C, Denk L, Neuderfer J. Integrating telemedicine in urban pediatric primary care: provider perspectives and performance. Telemed J E Health 2010;16:280-8.

27. Saigi-Rubió F, Jiménez-Zarco A, Torrent-Sellens J. Determinants of the intention to use telemedicine: evidence from primary care physicians. Int J Technol Assess Health Care 2016;32(1-2):29-36.

28. Robert Graham Center. Telehealth in primary care. ThinkAnthem Report; 2013. Available from: http:// 
thinkanthem.com/sites/default/files/TA-Telehealth_ full-advert.pdf.

29. Stingley S, Schultz H. Helmsley trust support for telehealth improves access to care in rural and frontier areas. Health Aff (Millwood) 2014;33: $336-41$.
30. AMD Global Telemedicine. Reasons telemedicine doesn't require tech-savvy doctors. Telemedicine Blog. May 7, 2016. Available from: http:// www.amdtelemedicine.com/blog/article/reasonstelemedicine-doesnt-require-tech-savvy-doctors. Accessed December 16, 2016. 